\title{
High Consumption of Green Tea Suppresses Urinary Tract Recurrence of Urothelial Cancer via Down-regulation of Human Antigen-R Expression in Never Smokers
}

\author{
TAKUJI YASUDA, YASUYOSHI MIYATA, YUICHIRO NAKAMURA, YUJI SAGARA, \\ TOMOHIRO MATSUO, KOJIRO OHBA and HIDEKI SAKAI
}

Department of Urology, Nagasaki University Graduate School of Biomedical Sciences, Nagasaki, Japan

\begin{abstract}
Background/Aim: Smoking is a risk factor for carcinogenesis and progression of urothelial cancer (UC). Green tea polyphenol inhibits these malignant behaviors and suppresses human antigen $R(H u R)$ expression, which is associated with malignant aggressiveness. This study aimed to clarify the anti-cancer effects of green tea based on the smoking status of UC patients. Patients and Methods: Three hundred and sixty (260 with bladder cancer, BC and 100 with upper tract UC) patients were divided into three groups based on consumption of green tea: low $(<1$ cup/day, $n=119)$, middle (1-4 cup/day, $n=160)$, and high (>5 cup/day, $n=81)$. HuR immunoreactivity was evaluated immunohistochemically in formalin-fixed specimens. Results: In never smokers, multivariate analysis showed that the frequency of green tea consumption was a significant predictor (middle: hazard ratio, $H R, 0.36, p=0.002$; high: HR, 0.20, $p=0.003$ ) of urinary tract recurrence. A high consumption of green tea was associated with low rates of urinary tract recurrence and up-grading in UC patients. In BC, high consumption was associated with a lower risk of up-grading $(p=0.011)$ and up-staging $(p=0.041)$ in recurrent cancer. HuR expression in the high-consumption group was lower $(p=0.019)$ than that in other groups. These significant findings were not detected in ever smokers. Conclusion: High consumption of green tea suppressed urinary tract recurrence and the risks of up-grading and up-staging by recurrence in never smokers. Our results suggested that HuR expression played important roles in such mechanisms.
\end{abstract}

This article is freely accessible online.

Correspondence to: Yasuyoshi Miyata, MD, Ph.D., Department of Urology, Nagasaki University Graduate School of Biomedical Science, 1-7-1 Sakamoto, Nagasaki 852-8501, Japan. Tel: +81 958197340, Fax: +81 958197343, e-mail: int.doc.miya@m3.dion.ne.jp

Key Words: Green tea, urothelial cancer, human antigen-R, smoking, recurrence.
Urothelial cancer (UC), including bladder cancer (BC) and upper-tract UC (UTUC), is one of the most common cancers worldwide. A representative characteristic of UC is the high frequency of recurrence in another urinary tract despite radical resection. Furthermore, some recurrent tumors show grade and stage up-regulation compared to primary tumors. Such increases in malignant potential and progression are often connected with an intimal step of metastasis and invasion into the surrounding tissues. In addition, importantly, treatment with a sufficient effect of prolonging survival periods has yet to be established in patients with advanced UC. Therefore, information about observation strategies after radical resection and the detailed mechanism of recurrence in the urinary tract is essential to improving the outcomes of UC patients.

Tea is the most popular beverage in the world, and about third quarter of them is black tea that is mostly consumed by Western countries (1). On the other hand, green tea is mainly consumed in Eastern countries such as China and Japan, where green tea comprises approximately $20 \%$ of all tea consumed (1). Green tea contains polyphenol (green tea polyphenol [GTP]) consisting of various types of catechins (2). Many pre-clinical studies have shown that green tea and GTP play important roles in the prevention and treatment of various types of malignancies (3). In addition, several animal studies showed that GTP led to a significant reduction in tumor incidence, development, and metastasis in in vivo models of prostate and breast cancer (4-6). Furthermore, epidemiological studies showed that increased green tea consumption was associated with a reduced risk of several cancers including prostate $(7,8)$ and breast (9). However, other investigators reported that no significant relationship was found in prostate or breast cancers $(10,11)$. Thus, there is no general consensus regarding the anti-cancer effects of green tea consumption. In bladder cancer, controversy persists regarding the relationships between green tea consumption and the risk of cancer, prevention of progression, and prolongation of survival. Briefly, although 
one study reported that green tea consumption significantly suppressed the risk of bladder cancer (12), several investigators showed that green tea consumption was not associated with such malignant potential $(8,13)$. In addition, one study reported that green tea consumption increased the risk of $\mathrm{BC}$ (14). Therefore, more detailed information regarding the anti-tumor mechanism of GTP at the molecular level in an in vivo study is essential to discussion of the clinical benefit, usefulness, and limitation of GTP intake.

Previous reports showed that GTP regulates various cancer-related molecules in several malignancies including BC $(15,16)$. Here special attention has been paid to human antigen-R (HuR) because its cytoplasmic (C-) expression was significantly associated with malignant aggressiveness and prognosis in $\mathrm{BC}$ patients (17). In addition, a recent study demonstrated that $\mathrm{C}-\mathrm{HuR}$ expression was suppressed by GTP in an animal model of BC (16). This study also focused in elucidating the relationships between pathological features, outcome, and $\mathrm{C}-\mathrm{HuR}$ expression by green tea consumption stratified by smoking status in UC patients because smoking has a strong influence on malignant behavior and prognosis. In short, we hypothesized that the anti-cancer effects of green tea consumption were cancelled by smoking.

The purpose of this study was to clarify the clinical impacts of smoking status for relationships between green tea consumption and pathological features in UC patients. Similar analyses were also performed in urinary tract recurrence and recurrent tumor up-grading and up-staging in these patients. Furthermore, to investigate the molecular mechanism of these findings, the relationship between green tea consumption and $\mathrm{C}-\mathrm{HuR}$ expression was analyzed according to smoking status in human UC tissues.

\section{Patients and Methods}

Patients. A total of 360 patients (260 with BC, 100 with UTUC) who were histologically diagnosed with urothelial cancer at Nagasaki University Hospital between 2003 and 2013 were investigated. Median (quantile range) age at diagnosis in all, BC, and UTUC patients were 70 (range $=62-77$ years), 71 (range $=62-78$ years), and 70 (range $=61-75$ years) years, respectively. Male patients comprised $284(78.9 \%), 208(80.0 \%)$, and $76(76.0 \%)$ of the BC, and UTUC total patient populations, respectively. The study excluded patients with metastasis, pure squamous cell carcinoma, adenocarcinoma, or small cell carcinoma as well as those for whom information on green tea consumption and smoking was missing. Patients who received any pre-operative therapy for UC were also excluded. The success of radical resection by histological examination was confirmed in all patients.

All patients were evaluated by chest radiography, ultrasonography and computed tomography (CT) of the urinary bladder and abdomen, and cystoscopy. In addition, CT of the lung or brain, magnetic resonance imaging, drip-infusion pyelography, and bone scans were performed as deemed necessary. Staging was assessed in accordance
Table I. Green tea consumption and smoking status.

\begin{tabular}{lrrrr}
\hline & $\mathrm{n}$ & \multicolumn{2}{c}{ Smoking status; $\mathrm{n} / \%$} & \multirow{2}{*}{-Value } \\
\cline { 3 - 4 } & & Never & Ever & \\
\cline { 3 - 4 } & & & & \\
Green tea consumption & 360 & $166 / 46.1$ & $194 / 53.9$ & \multirow{2}{*}{0.258} \\
Entire patients; $\mathrm{n} / \%$ & 119 & $61 / 51.3$ & $58 / 58.7$ & \\
Low $(<1$ cup/day) & 160 & $73 / 45.6$ & $87 / 54.4$ & \\
Middle (1-4 cups/day) & 81 & $32 / 39.5$ & $49 / 60.5$ & \\
High ( $\geq 5$ cups/day) & 260 & $115 / 44.2$ & $145 / 55.8$ & 0.698 \\
Bladder cancer & 90 & $43 / 47.8$ & $47 / 52.2$ & \\
Low (<1 cup/day) & 110 & $47 / 77.5$ & $63 / 32.5$ & \\
Middle (1-4 cups/day) & 60 & $25 / 41.7$ & $35 / 58.3$ & \\
High ( $\geq 5$ cups/day) & 100 & $51 / 51.0$ & $49 / 49.0$ & 0.131 \\
Upper tract urothelial cancer & 29 & $18 / 62.1$ & $11 / 37.9$ & \\
Low (<1 cup/day) & 50 & $26 / 22.0$ & $24 / 48.0$ & \\
Middle (1-4 cups/day) & 21 & $7 / 33.3$ & $14 / 66.7$ & \\
High ( $\geq 5$ cups/day) & & &
\end{tabular}

with the 2009 tumor-node-metastasis classification. Tumor grade was assigned according to the 2004 World Health Organization grading system. Cystoscopy was performed every 3 months for 3 years after treatment and annually for an additional 2 years, while cytology and CT were performed every 6 months for 5 years.

Data collection. Patients were asked about their green tea consumption and smoking status by interview and a standardized questionnaire at the time of diagnosis. In this study, the cup size was equivalent to $200 \mathrm{ml}$. Daily tea consumption was categorized into three groups based on its consumption: 1 cup/several days (low), 1-4 cups/day (middle), and $\geq 5$ cups/day (high). In regard to the smoking status, individuals who never smoked or smoked $<100$ cigarettes in their lifetime were defined as never smokers. The study was approved by the Institutional Review Board of Nagasaki University Hospital, while written informed consent was obtained from all participants.

Immunohistochemistry. C-HuR expression was evaluated as previously described (17). Briefly, immunohistochemical analyses were performed using formalin-fixed, paraffin-embedded tissue sections. The 5- $\mu \mathrm{m}$ tissue sections were deparaffinized in xylene and rehydrated in ethanol. Antigen retrieval was performed by heating at $100^{\circ} \mathrm{C}$ for $15 \mathrm{~min}$ in $0.01 \mathrm{M}$ sodium citrate buffer $(\mathrm{pH}$ 6.0). All tissue sections were then immersed in $3 \%$ hydrogen peroxide for $30 \mathrm{~min}$ to block endogenous peroxidase activity. The tissue sections were incubated overnight with the primary antibody (HuR [H-280]: sc-20694, Santa Cruz Biotechnology, Dallas, TX, USA; $1: 100)$ at $4^{\circ} \mathrm{C}$, then incubated with peroxidase using the labeled polymer method with Dako EnVision ${ }^{\mathrm{TM}}$ Peroxidase (Dako North America, Inc., Carpinteria, CA, USA) for $60 \mathrm{~min}$ at room temperature. The peroxidase reaction was visualized using a liquid 3,3'-diaminobenzidine tetrahydrochloride substrate kit (Thermo Fisher Scientific, Inc., Waltham, MA, USA). The tissue sections were then counterstained with hematoxylin.

C-HuR expression was evaluated based on immunoreactive staining score as previously reported $(17,18)$. In short, C-HuR immunostaining in cancer cells was scored as follows: 0 , no 
staining; 1 , weak or focal staining in $<10 \%$ of cells; 2 , moderate or intense staining in $10-50 \%$ of cells; and 3 , moderate or intense staining in $>50 \%$ of cells. A score of 0 or 1 indicated low C-HuR expression, whereas a score of 2 or 3 indicated high $\mathrm{C}-\mathrm{HuR}$ expression. The tissue sections were observed using an E-400 light microscope (Nikon Corporation, Tokyo, Japan) to obtain digital images, while the computer-aided image analysis system WinROOF version 5.0 (Mitani Corporation, Fukui, Japan) was used to evaluate $\mathrm{C}-\mathrm{HuR}$ expression.

Statistical analyses. Results are expressed as mean $\pm \mathrm{SD}$, and Student's $t$-test was applied to continuous variables. The chi-square test was used for categorical data comparisons. The Kaplan-Meier survival curve and log-rank test were used, as was the Cox proportional hazards model multivariate analysis. Data of the logistic regression analyses are shown as odds ratio (OR), 95\% confidential interval (CI), and $p$-values. Values of $p<0.05$ were considered statistically significant. All statistical analyses were performed using StatView v.5.0 for Windows (Abacus Concepts, San Francisco, CA, USA).

\section{Results}

Correlation with smoking status, clinicopathological features, and recurrence. Of all patients $(\mathrm{n}=360), 119$ $(33.1 \%), 160(44.4 \%)$, and $81(22.5 \%)$ had low, middle, and high green tea intake, respectively. As shown in Table I, there was no significant relationship between green tea consumption and smoking status in all $(p=0.258), \mathrm{BC}$ $(p=0.698)$, and UTUC $(p=0.131)$ patients. Furthermore, green tea consumption was not significantly associated with grade and pT stage in all, BC, and UTUC patients (Table II). Kaplan-Meier survival curves are shown in Figure 1. As shown in Figure 1A, a low intake of green tea had a worse prognosis for urinary tract recurrence in all patients; however, this difference did not reach significance $(p=0.144)$. When a similar analysis was performed separately for BC and UTUC patients, green tea consumption was not associated with urinary tract recurrence-free survival in either patient group ( $p=0.362$ and 0.263 , respectively; Figure 1B and C).

Malignant behavior according to smoking status. When the relationship between green tea consumption and grade were investigated by smoking status, no significant relationship was detected in never smokers $(p=0.867)$ or ever smokers $(p=0.878)$. Regarding green tea consumption and $\mathrm{pT}$ stage, there was no significant relationship between never smokers $(p=0.122)$ and ever smokers $(p=0.771)$. However, survival analyses showed that green tea consumption was significantly associated with urinary tract recurrence-free survival in neversmoker all, BC, and UTUC patients ( $p=0.003,0.042,0.039$, respectively; Figure 1D, F). On the other hand, no significant relationship was not detected in all ever-smoker, BC, and UTUC patients ( $p=0.900,0.940,0.553$, respectively). When multivariate analysis models including all clinicopathological features and intravesical therapy were investigated, green tea consumption was identified as a significant and independent predicative factor of urinary tract recurrence in never smokers (middle intake: hazard ratio [HR], 0.36, 95\% CI=0.19-0.70, $p=0.002$; high intake: $\mathrm{HR}=0.20,95 \% \mathrm{CI}=0.07-0.57, p=0.03$ ) but not in ever smokers (Table III).

Correlation with up-regulation of grade and pT stage by recurrence. In this study, 141 patients (39.2\%) developed urinary tract recurrence. To investigate the relationship between green tea consumption and up-grading by urinary tract recurrence, patients with grade 3 primary tumors were excluded. Finally, 75 and 62 all and BC patients were analyzed, respectively. On the other hand, only patients with non-muscle invasive disease (pTa and 1) were investigated (all=130; $\mathrm{BC}=105$ ) about up-pT stage. Univariate analyses showed that a high green tea intake was associated with a low risk of up-grading in recurrent cancer in all $(\mathrm{OR}=0.13$, $95 \% \mathrm{CI}=0.03-0.68, p=0.015)$ and $\mathrm{BC}(\mathrm{OR}=0.11,95 \% \mathrm{CI}=0.02-$ $0.59, p=0.011)$ patients. Similar univariate analyses showed that a high green tea intake was identified as a suppressor of up-pT stage in $\mathrm{BC}$ patients $(\mathrm{OR}=0.11,95 \% \mathrm{CI}=0.01-0.91$, $p=0.041)$ but not in all patients $(\mathrm{OR}=0.24,95 \% \mathrm{CI}=0.05-1.16$, $p=0.076$ ). As shown in Table IV, multivariate analysis models including all clinicopathological features (sex, age, grade, and pT stage), intravesical therapy, and smoking status showed that a high frequency of green tea consumption was an independent factor for a low risk of up-grading of recurrent tumors in all $(\mathrm{OR}=0.12,95 \% \mathrm{CI}=0.02-0.72, p=0.021)$ and $\mathrm{BC}$ patients $(\mathrm{OR}=0.12,95 \% \mathrm{CI}=0.02-0.75, p=0.024)$. On the other hand, a high green tea consumption was significantly associated with up-staging of $\mathrm{pT}$ in $\mathrm{BC}$ patients $(\mathrm{OR}=0.09$, $95 \% \mathrm{CI}=0.01-0.81, p=0.032$ ) but not in all patients (Table IV).

Correlation with HuR expression. In all patients, the positive ratio of $\mathrm{C}-\mathrm{HuR}$ expression in a high frequency of green tea consumption tended to be lower than that in low green tea consumption; however, it did not reach significance ( $p=0.176$; Figure 2). Figure 2 also showed that the ratio in high green tea consumption (19.4\%) was significantly lower $(p=0.019)$ compared to those in the never smokers of the low $(48.3 \%)$ or middle green tea consumption $(45.8 \%)$ groups; however, such a significant relationship was not found in ever smokers $(p=0.889)$. The relationship between C-HuR expression and grade or muscle invasion according to green tea consumption is shown in Figure $3 \mathrm{~A}$ and $\mathrm{B}$. In patients with a low frequency of green tea consumption, C-HuR expression was positively associated with both grade $(p=0.028)$ and muscle invasion $(p<0.001)$. Middle intake was significantly related with muscle invasion $(p=0.005)$ but not grade $(p=0.513)$. On the other hand, high intake was not associated with grade $(p=0.960)$ or muscle invasion 

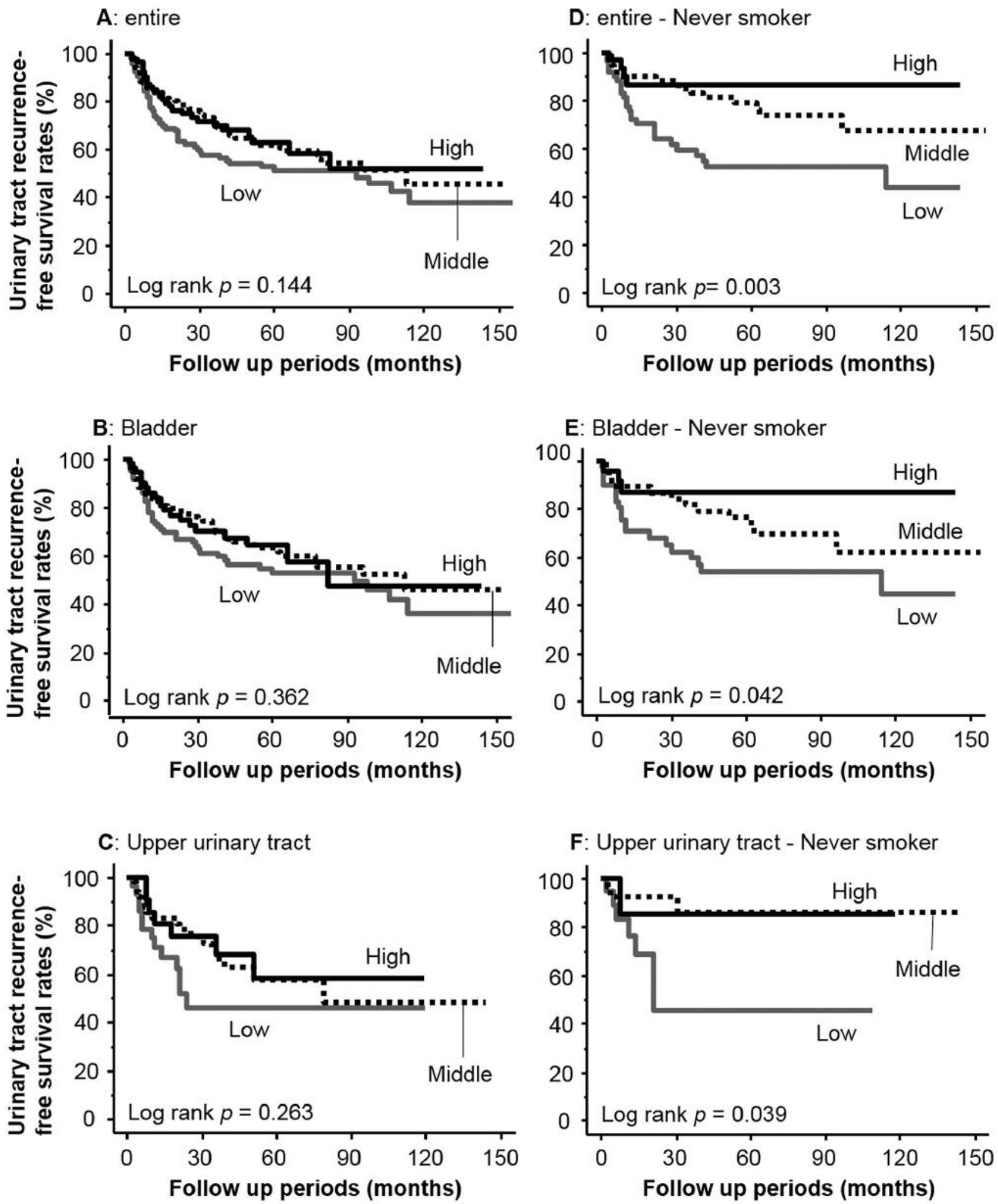

Figure 1. Kaplan-Meier survival curves of recurrence in the urinary tract. There was no significant difference between green tea intake and recurrence-free survival rates in entire (A), bladder cancer $(B)$, and upper urinary tract cancer $(C)$ patients. On the other hand, when similar analyses were performed in never smokers, the frequency of green tea intake was significantly associated in all (D), bladder cancer (E), and upper urinary tract cancer $(F)$ patients. 
Table II. Relationships between green tea consumption and pathological features.

\begin{tabular}{|c|c|c|c|c|c|c|c|}
\hline & \multicolumn{3}{|c|}{ Grade; $\mathrm{n} / \%$} & \multicolumn{4}{|c|}{ Pathological T stage; $\mathrm{n} / \%$} \\
\hline & Grade 1 & Grade 2 & Grade 3 & $\mathrm{Ta}$ & $\mathrm{T} 1$ & $\mathrm{~T} 2$ & $\mathrm{~T} 3$ \\
\hline Entire & $84 / 23.3$ & $131 / 36.4$ & $145 / 40.3$ & $115 / 31.9$ & $153 / 42.5$ & $56 / 15.6$ & $36 / 10.0$ \\
\hline Low & $29 / 24.3$ & $39 / 32.8$ & $51 / 42.9$ & $39 / 32.8$ & $55 / 46.2$ & $14 / 11.8$ & $11 / 9.2$ \\
\hline Middle & $34 / 21.3$ & $62 / 38.8$ & $64 / 40.0$ & $49 / 30.6$ & $65 / 40.6$ & $26 / 16.3$ & $20 / 12.5$ \\
\hline High & $21 / 25.9$ & $30 / 37.0$ & $30 / 37.0$ & $27 / 33.3$ & $33 / 40.7$ & $16 / 19.8$ & $5 / 6.2$ \\
\hline$p$-Value & & 0.795 & & \multicolumn{4}{|c|}{0.433} \\
\hline $\mathrm{BC}$ & $68 / 26.2$ & $109 / 41.9$ & $58 / 22.3$ & $99 / 38.1$ & $123 / 47.3$ & $38 / 14.6$ & - \\
\hline Low & $24 / 26.7$ & 28/31.1 & $38 / 42.2$ & $37 / 41.1$ & $41 / 45.6$ & $12 / 13.3$ & - \\
\hline Middle & $29 / 26.4$ & $40 / 36.4$ & $41 / 37.3$ & $40 / 36.4$ & $55 / 50.0$ & $15 / 13.6$ & - \\
\hline High & $15 / 25.0$ & $22 / 36.7$ & $23 / 38.3$ & $22 / 36.7$ & $27 / 45.0$ & $11 / 18.3$ & - \\
\hline$p$-Value & & 0.931 & & \multicolumn{4}{|c|}{0.346} \\
\hline UTUC & $16 / 16.0$ & $41 / 41.0$ & $43 / 43.0$ & $16 / 16.0$ & $30 / 30.0$ & $18 / 18.0$ & $36 / 36.0$ \\
\hline Low & $5 / 17.2$ & $11 / 37.9$ & $13 / 44.8$ & 2/6.9 & $14 / 48.3$ & $2 / 6.9$ & $11 / 30.6$ \\
\hline Middle & $5 / 10.0$ & $22 / 44.0$ & $23 / 46.0$ & $9 / 18.0$ & $10 / 20.0$ & $11 / 22.0$ & $20 / 40.0$ \\
\hline High & $6 / 28.6$ & $8 / 38.1$ & $7 / 33.3$ & $5 / 23.8$ & $6 / 28.6$ & $5 / 23.8$ & $5 / 23.8$ \\
\hline$p$-Value & & 0.402 & & \multicolumn{4}{|c|}{0.080} \\
\hline
\end{tabular}

BC: Bladder cancer; UTUC: upper tract urothelial cancer.

Table III. Multivariate analyses for urinary tract recurrence according to smoking status

\begin{tabular}{|c|c|c|c|c|c|c|}
\hline & \multicolumn{3}{|c|}{ Never smoker } & \multicolumn{3}{|c|}{ Ever smoker } \\
\hline & HR & $95 \% \mathrm{CI}$ & $p$-Value & HR & $95 \% \mathrm{CI}$ & $p$-Value \\
\hline \multicolumn{7}{|l|}{ Gender } \\
\hline Male & 0.56 & $0.31-1.02$ & 0.058 & 0.94 & $0.37-2.38$ & 0.990 \\
\hline \multicolumn{7}{|l|}{ Age at diagnosis } \\
\hline Over median & 1.34 & $0.72-2.49$ & 0.355 & 0.77 & $0.50-1.18$ & 0.227 \\
\hline \multicolumn{7}{|l|}{ Site } \\
\hline Bladder & 1.44 & $0.60-3.45$ & 0.418 & 1.22 & $0.67-2.22$ & 0.514 \\
\hline \multicolumn{7}{|l|}{ Grade } \\
\hline 2 & 0.78 & $0.35-1.73$ & 0.541 & 1.17 & $0.67-2.06$ & 0.583 \\
\hline 3 & 1.46 & $0.71-3.01$ & 0.301 & 1.48 & $0.83-2.65$ & 0.183 \\
\hline \multicolumn{7}{|l|}{ pT stage } \\
\hline 1 & 0.82 & $0.42-1.57$ & 0.546 & 1.35 & $0.79-2.33$ & 0.274 \\
\hline 2 and 3 & 0.84 & $0.35-2.01$ & 0.693 & 2.24 & $1.16-4.32$ & 0.016 \\
\hline \multicolumn{7}{|l|}{ Intravesical therapy } \\
\hline Not performed & 1.47 & $0.69-3.11$ & 0.316 & 1.08 & $0.64-1.81$ & 0.773 \\
\hline \multicolumn{7}{|c|}{ Green tea consumption } \\
\hline Middle & 0.36 & $0.19-0.70$ & 0.002 & 1.03 & $0.64-1.66$ & 0.894 \\
\hline High & 0.20 & $0.07-0.57$ & 0.003 & 0.90 & $0.51-1.58$ & 0.703 \\
\hline
\end{tabular}

HR: Hazard ratio; CI: confidential interval.

$(p=0.088)$. When relationships between up-grading of recurrent tumor and $\mathrm{C}-\mathrm{HuR}$ expression were analyzed, CHuR expression was not significantly associated in all $(p=0.251)$ or $\mathrm{BC}(p=0.638)$ patients. A similar analysis also showed that up-staging in $\mathrm{BC}$ patients was not associated with C-HuR expression $(p=0.432)$.

\section{Discussion}

Our results demonstrated that that anti-cancer effects including the prevention of urinary tract recurrence by green tea consumption in UC patients varied based on their smoking status. We previously reported that GTP intake 


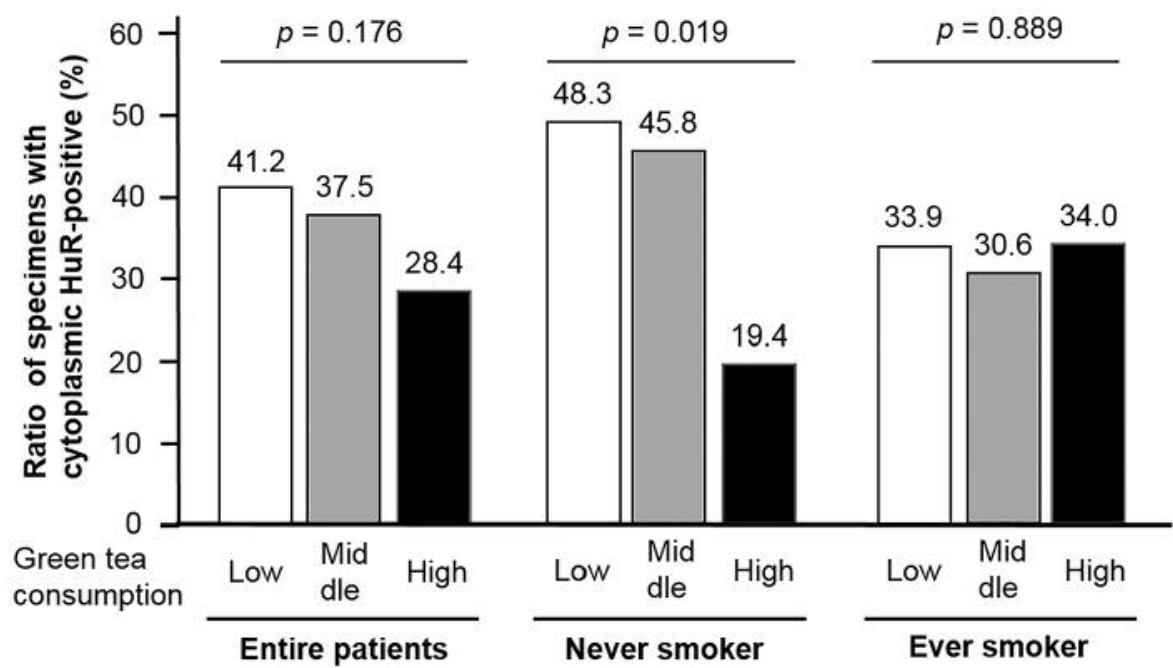

Figure 2. Green tea consumption was negatively associated with cytoplasmic human antigen $R(H u R)$ expression in bladder cancer tissues in never smokers, but not in ever smokers.

Table IV. Independent role for changing by recurrence in multi-variate analyses.

\begin{tabular}{|c|c|c|c|c|c|c|}
\hline & \multicolumn{3}{|c|}{ Entire } & \multicolumn{3}{|c|}{ Bladder cancer } \\
\hline & OR & $95 \% \mathrm{CI}$ & $p$-Value & OR & $95 \% \mathrm{CI}$ & $p$-Value \\
\hline \multicolumn{7}{|c|}{ For up-grade } \\
\hline \multicolumn{7}{|c|}{ Smoking status } \\
\hline Never & 1.91 & $0.48-7.54$ & 0.358 & 1.51 & $0.36-6.47$ & 0.579 \\
\hline \multicolumn{7}{|c|}{ Green tea intake } \\
\hline Middle & 0.59 & $0.19-1.82$ & 0.358 & 0.42 & $0.12-1.42$ & 0.162 \\
\hline High & 0.12 & $0.02-0.73$ & 0.021 & 0.12 & $0.02-0.75$ & 0.024 \\
\hline \multicolumn{7}{|c|}{ For up-stage } \\
\hline \multicolumn{7}{|c|}{ Smoking status } \\
\hline Never & 1.49 & $0.46-4.83$ & 0.509 & 1.57 & $0.46-5.34$ & 0.470 \\
\hline \multicolumn{7}{|c|}{ Green tea intake } \\
\hline Middle & 0.52 & $0.20-1.37$ & 0.185 & 0.52 & $0.07-1.43$ & 0.205 \\
\hline High & 0.19 & $0.04-1.01$ & 0.051 & 0.09 & $0.01-0.81$ & 0.032 \\
\hline
\end{tabular}

OR: Odds ratio; CI: confidential interval.

suppressed malignant behaviors in an N-butyl-N-(4hydroxybutyl)-nitrosamine-induced BC mouse model (19), and this result was supported by other reports $(16,20)$. In addition, several cell-based studies support such anti-cancer effects of GTP in BC $(21,22)$. However, the anti-cancer effects of green tea consumption were controversial in epidemiological studies $(8,12,13)$. Based on these facts, we speculated that something decreased the anti-cancer effects of green tea in BC patients. Therefore, special attention was paid to smoking status in this study because smoking is known to up-regulate malignant aggression in UC (23). Finally, we hypothesized that anti-cancer effects by green tea consumption were modulated by smoking in UC patients.

Our results also showed that a high consumption of green tea decreased the risk of urinary tract recurrence in UC of never smokers but not ever smokers. The present study is the first to report the anti-cancer effects of green tea consumption based on the smoking status of UC patients. Unfortunately, the direct effects of smoking on anti-cancer activities of GTP in UC have not yet been studied. However, in oral cancer, the risk was significantly decreased in tea drinkers and non-passive smokers ( $\mathrm{OR}=0.537$, $95 \% \mathrm{CI}=0.294-0.982$ ), but not in tea drinkers and passive 


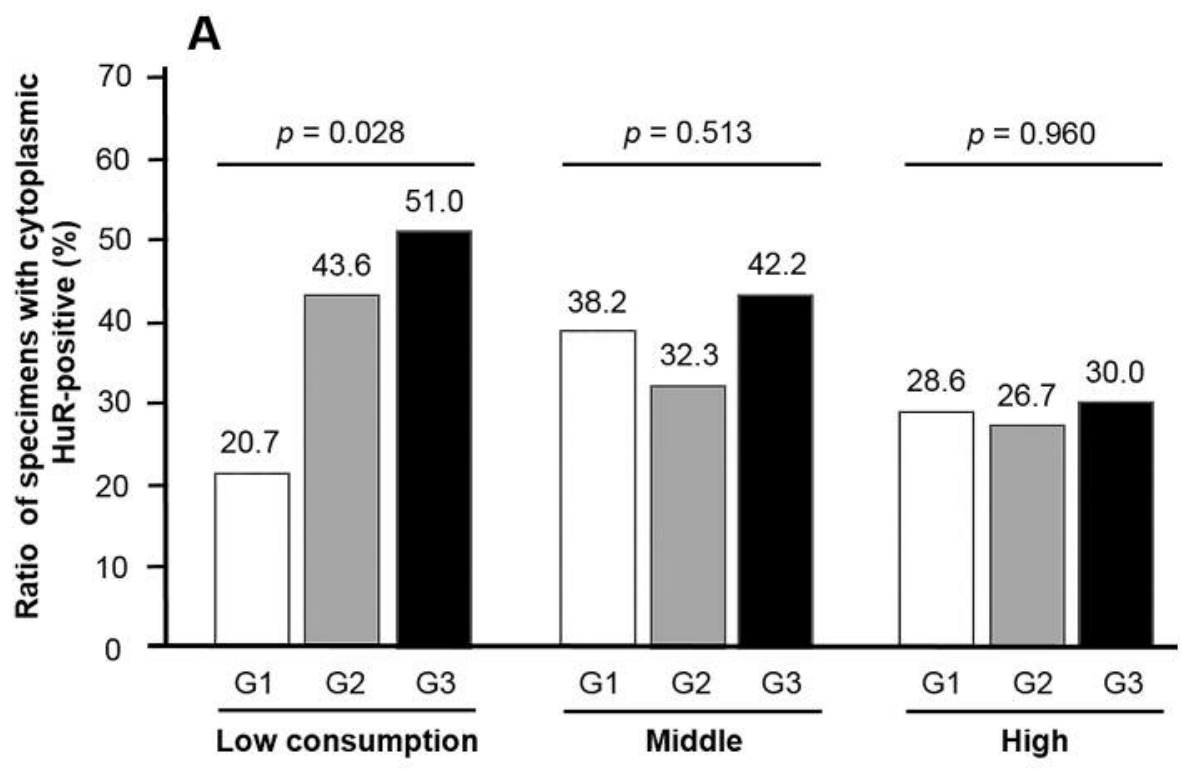

B

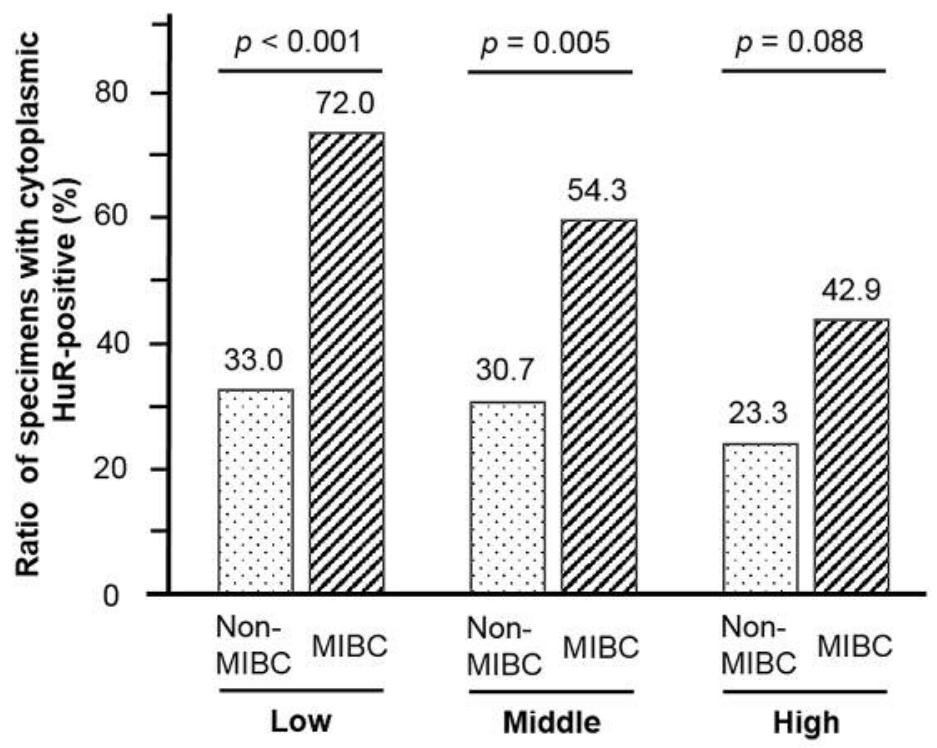

Figure 3. Cytoplasmic human antigen $R(H u R)$ expression was positively associated with grade in bladder cancer patients with a low consumption of green tea; however, such a significant difference was not found in patients with a middle or high consumption (A). Regarding muscle invasion, cytoplasmic $H u R$ expression was significantly associated in patients with a low or middle consumption of green tea, but not in those with a high consumption (B).

smokers $(\mathrm{OR}=0.812,95 \% \mathrm{CI}=0.397-1.659)(24)$. Thus, it is possible that smoking decreases the anti-cancer effects of green tea in UC patients. On the other hand, our results also showed that smoking status did not affect the relationship between green tea consumption and pathological features. The difference in the anti-cancer effects of green tea consumption by smoking status cannot be explained. However, it is possible that GTP and smoking may regulate the pathological characteristics of UC by a very complex mechanism at the molecular level because they modulate many cancer-related factors.

One of the most interesting results is that $\mathrm{C}-\mathrm{HuR}$ expression was associated with green tea consumption in the tissues of UC patients. HuR is involved in posttranscriptional regulation of RNA turnover and stability (25). In various cancers, HuR regulates various cancer-related 
molecules including vascular endothelial growth factors, cyclooxygenase, and matrix metalloproteins via stability of their mRNA (26-29). These HuR-related molecules play important roles in carcinogenesis, cancer cell proliferation, angiogenesis, and tumor invasion in UC (30-33). In fact, HuR was reportedly associated with metastasis and survival via the regulation of cancer cell proliferation, angiogenesis, and expression of vascular endothelial growth factor-A and $-\mathrm{C}$ in BC patients (17). On the other hand, HuR expression in malignant cells was reportedly suppressed by GTP (34). In addition, a recent study showed that GTP intake inhibited cytoplasmic HuR expression in a BC animal model (16). From these findings, it is suggested that a high frequency of green tea decreased the risk of urinary tract recurrence by down-regulating C-HuR expression in UC patients.

Another interesting result of this study is that a high frequency of green tea consumption was negatively associated with recurrent tumor up-grading and up-staging. Tumor grade is a strong predictor of progression and survival as well as an important factor in the determination of treatment strategies including surgical methods and adjuvant therapy. Therefore, up-grading of recurrent tumors contribute to improving the prognosis of UC patients. Our results showed that a high frequency of green tea consumption is useful information in the discussion of treatment strategies for these patients. On the other hand, unfortunately, there is little information regarding the detailed mechanism of up-grading and up-staging of recurrent tumors in UC. Although we hypothesized that decreased expressions of C-HuR may affect such a mechanism, it was not associated. Finally, more studies are required to conclude that $\mathrm{C}-\mathrm{HuR}$ plays any important role in up-grading and up-staging by unknown indirect mechanisms.

Our study had some limitations. First, some difficulties were encountered in obtaining accurate information regarding the patients' green tea consumption. In this study, almost all patients used a traditional cup in Japan rather than a bottle or coffee cup. Second, to reduce the impact of recall bias, only patients who were newly diagnosed were analyzed. Third, although the anti-cancer effects of green tea were analyzed in a relatively small cancer patient study population, this study comprised the largest number of patients in the analysis of green tea and smoking.

\section{Conclusion}

Our results demonstrated that a high consumption of green tea was associated with low rates of urinary tract recurrence and up-grading in UC patients. In addition, a similar negative association between green tea consumption and up-staging in recurrent tumors was detected in BC patients. HuR expression was significantly lower in the high-green tea consumption group than in the other groups. Importantly, these significant relationships were detected in never smokers but not in the ever smokers. It is possible that the anti-cancer effects of green tea consumption via the regulation of cytoplasmic HuR expression were negated by smoking in UC patients. Although more detailed and largescale studies are necessary to confirm these findings, we believe that a high frequency of green tea consumption is a useful tool for preventing urinary tract recurrence and progression in never-smoker UC patients.

\section{Conflicts of Interest}

The Authors declare that they have no conflict of interest.

\section{References}

1 Katiyar SK and Elmets CA: Green tea polyphenolic antioxidants and skin photoprotection. Int J Oncol 18: 1307-1313, 2001.

2 Balentine DA, Wiseman SA and Bouwens LC: The chemistry of tea flavonoids. Crit Rev Food Sci Nutr 37: 693-704, 1997.

3 Mineva ND, Paulson KE, Naber SP, Yee AS and Sonenshein GE: Epigallocatechin-3-gallate inhibits stem-like inflammatory breast cancer cells. PLoS One 8: e73464, 2013.

4 Gupta S, Hastak K, Ahmad N, Lewin JS and Mukhtar H: Inhibition of prostate carcinogenesis in TRAMP mice by oral infusion of green tea polyphenols. Proc Natl Acad Sci USA 98: 10350-10355, 2001.

5 Caporali A, Davalli P, Astancolle S, D’Arca D, Brausi M, Bettuzzi S and Corti S: The chemopreventive action of catechins in the TRAMP mouse model of prostate carcinogenesis is accompanied by clusterin over-expression. Carcinogenesis 25 : 2217-2224, 2004.

6 Baliga MS, Meleth S and Katiyar SK: Growth inhibitory and antimetastatic effect of green tea polyphenols on metastasisspecific mouse mammary carcinoma $4 \mathrm{~T} 1$ cells in vitro and in vivo systems. Clin Cancer Res 11: 1918-1927, 2005.

7 Jian L, Xie LP, Lee AH and Binns CW: Protective effect of green tea against prostate cancer: a case-control study in southeast China. Int J Cancer 108: 130-135, 2004.

8 Boehm K, Borrelli F, Ernst E, Habacher G, Hung SK, Milazzo $\mathrm{S}$ and Horneber M: Green tea (Camellia sinensis) for the prevention of cancer. Cochrane Database Syst Rev 8: CD005004, 2009.

$9 \mathrm{Wu} \mathrm{AH}, \mathrm{Yu} \mathrm{MC}$, Tseng CC, Hankin J, and Pike MC: Green tea and risk of breast cancer in Asian Americans. Int J Cancer 106: 574-579, 2003.

10 Slattery ML and West DW: Smoking, alcohol, coffee, tea, caffeine, and theobromine: risk of prostate cancer in Utah (United States). Cancer Causes Control 4: 559, 1993.

11 Suzuki Y, Tsubono Y, Nakaya N, Suzuki Y, Koizumi Y and Tsuji I: Green tea and the risk of breast cancer: pooled analysis of two prospective studies in Japan. Br J Cancer 90: 1361-1363, 2004.

12 Wang X, Lin YW, Wang S, Wu J, Mao QQ, Zheng XY and Xie LP: A meta-analysis of tea consumption and the risk of bladder cancer. Urol Int 90: 10-16, 2013.

13 Hemelt M, Hu Z, Zhong Z, Xie LP, Wong YC, Tam PC, Cheng KK, Ye Z, Bi X, Lu Q, Mao Y, Zhong WD and Zeegers MP: Fluid intake and the risk of bladder cancer: results from the South and East China case-control study on bladder cancer. Int J Cancer 127: 638-645, 2010. 
14 Wakai K, Hirose K, Takezaki T, Hamajima N, Ogura Y, Nakamura S, Hayashi $\mathrm{N}$ and Tajima K: Foods and beverages in relation to urothelial cancer: case-control study in Japan. Int $\mathrm{J}$ Urol 11: 11-19, 2004.

15 Yang CS and Wang H: Mechanistic issues concerning cancer prevention by tea catechins. Mol Nutr Food Res 55: 819-831, 2011.

16 Matsuo T, Miyata Y, Asai A, Sagara Y, Furusato B, Fukuoka J and Sakai H: Green tea polyphenol induces changes in cancerrelated factors in an animal model of bladder cancer. PLoS One 12: e0171091, 2017.

17 Miyata Y, Watanabe S, Sagara Y, Mitsunari K, Matsuo T, Ohba $\mathrm{K}$ and Sakai H: High expression of HuR in cytoplasm, but not nuclei, is associated with malignant aggressiveness and prognosis in bladder cancer. PLoS One 8: e59095, 2013.

18 Costantino CL, Witkiewicz AK, Kuwano Y, Cozzitorto JA, Kennedy EP, Dasgupta A, Keen JC, Yeo CJ, Gorospe M and Brody JR: The role of HuR in gemcitabine efficacy in pancreatic cancer: HuR up-regulates the expression of the gemcitabine metabolizing enzyme doxycytidine kinase. Cancer Res 69: 45674572, 2009.

19 Sagara Y, Miyata Y, Nomata K, Hayashi T and Kanetake H: Green tea polyphenol suppresses tumor invasion and angiogenesis in N-butyl-(-4-hydroxybutyl) nitrosamine-induced bladder cancer. Cancer Epidemiol 34: 350-354, 2010.

20 Hsieh DS, Wang H, Tan SW, Huang YH, Tsai CY, Yeh MK and Wu CJ: The treatment of bladder cancer in a mouse model by epigallocatechin-3-gallate-gold nanoparticles. Biomaterials 32: 7633-7640, 2011.

21 Chen JJ, Ye ZQ and Koo MW: Growth inhibition and cell cycle arrest effects of epigallocatechin gallate in the NBT-II bladder tumour cell line. BJU Int 93: 1082-1086, 2004.

22 Qin J, Xie B, Mao Q, Kong D, Lin Y and Zheng X: Tea consumption and risk of bladder cancer: a meta-analysis. World J Surg Oncol 10: 172, 2012.

23 Miyata Y, Mitsunari K, Akihiro A, Watanabe SI, Mochizuki Y and Sakai H: Smoking-induced changes in cancer-related factors in patients with upper tract urothelial cancer. Mol Clin Oncol 3: 287-294, 2015.

24 Chen L, Mo H, Zhao L, Gao W, Wang S, Cromie MM, Lu C, Wang JS and Shen CL: Therapeutic properties of green tea against environmental insults. J Nutr Biochem 40: 1-13, 2017.

25 Hinman $\mathrm{MN}$ and Lou $\mathrm{H}$ : Diverse molecular functions of $\mathrm{Hu}$ proteins. Cell Mol Life Sci 65: 3168-3181, 2008.
26 Akool el-S, Kleinert H, Hamada FM, Abdelwahab MH, Förstermann U, Pfeilschifter J and Eberhardt W: Nitric oxide increases the decay of matrix metalloproteinase 9 mRNA by inhibiting the expression of mRNA-stabilizing factor HuR. Mol Cell Biol 23: 4901-4916, 2003.

27 Sakuma T, Nakagawa T, Ido K, Takeuchi H, Sato K and Kubota T: Expression of vascular endothelial growth factor-A and mRNA stability factor HuR in human meningiomas. J Neurooncol 88: 143-155, 2008.

28 Wang J, Zhao W, Guo Y and Zhang C: The expression of RNAbinding protein HuR in non-small cell lung cancer correlated with vascular endothelial growth factor-C expression and lymph node metastasis. Oncology 76: 420-429, 2009.

29 Kurosu T, Ohga N, Hida Y, Maishi N, Akiyama K, Kakuguchi W, Kuroshima T, Kondo M, Akino T, Totsuka Y, Shindoh M, Higashino $\mathrm{F}$ and Hida $\mathrm{K}$ : HuR keeps an angiogenic switch on by stabilising mRNA of VEGF and COX-2 in tumour endothelium. Br J Cancer 104: 819-829, 2011.

30 Miyata Y, Kanda S, Ohba K, Nomata K, Hayashida Y, Eguchi J, Hayashi $\mathrm{T}$ and Kanetake $\mathrm{H}$ : Lymphangiogenesis and angiogenesis in bladder cancer: prognostic implications and regulation by vascular endothelial growth factors-A, -C, and -D. Clin Cancer Res 12: 800-806, 2006.

31 Chen CC, Hsieh TF, Chang CH, Ma WL, Hung XF, Tsai YR, Lin $\mathrm{MH}$, Zhang $\mathrm{C}$, Chang $\mathrm{C}$ and Shyr CR: Androgen receptor promotes the migration and invasion of upper urinary tract urothelial carcinoma cells through the upregulation of MMP-9 and COX-2. Oncol Rep 30: 979-985, 2013.

32 Gakis G: The role of inflammation in bladder cancer. Adv Exp Med Biol 816: 183-196, 2014.

33 Soukup V, Čapoun O, Pešl M, Sobotka R, Vávřová L, Hanuš T, Zima T and Kalousová M: Placental growth factor in bladder cancer compared to the diagnostic accuracy and prognostic performance of vascular endothelial growth factor A. Anticancer Res 38: 239-246, 2018.

34 Annabi B, Currie JC, Moghrabi A and Béliveau R: Inhibition of HuR and MMP-9 expression in macrophage-differentiated HL60 myeloid leukemia cells by green tea polyphenol EGCg. Leuk Res 31: 1277-1284, 2007.

Received March 31, 2018

Revised April 24, 2018

Accepted April 25, 2018 